IJBPAS, November, Special Issue, 2021, 10(11): 1510-1527

ISSN: 2277-4998

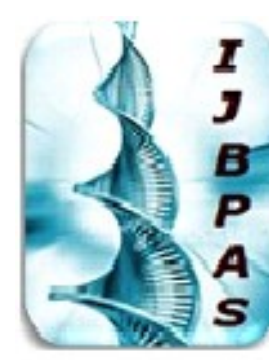

International Journal of Biology, Pharmacy and Allied Sciences (IJBPAS)

'A Bridge Betuen Caboratory and QRendor'

www.ijbpas.com

FISETIN INDUCES APOPTOSIS IN HT-29 COLON CANCER CELLS

THROUGH MODULATION OF NF-KB AND IL-6/STAT3 SIGNALING

\title{
S.KUNCHARI KALAIMATHI* AND G.SUDHANDIRAN
}

Department of Biochemistry, Guindy Campus, University of Madras, Chennai - 600025,

Tamilnadu, India

*Corresponding Author: S.Kunchari Kalaimathi; E Mail: kuncharik@gmail.com

Received 26 ${ }^{\text {th }}$ July 2021; Revised $27^{\text {th }}$ Aug. 2021; Accepted $1^{\text {st }}$ Oct. 2021; Available online $1^{\text {st }}$ Nov. 2021

https://doi.org/10.31032/IJBPAS/2021/10.11.1130

\begin{abstract}
Fisetin(3,7,3',4-tetrahydroxyflavone) belongs to a subgroup of flavonoids, that are widely present in the fruits and vegetables. Fisetin possess many beneficial properties which include antioxidant activities, anti-toxicity, anti-hyperlipidemic, neuroprotective and antiproliferative actions. Colorectal cancer is the second leading cause of cancer death worldwide. In healthy cells, regulation of apoptosis plays vital role in maintaining normal colonic epithelia, and any deregulation often leads to colon cancer. The IL-6/JAK/STAT3 signaling pathway plays important role in the colorectal tumorigenesis. In IL-6/JAK/STAT signaling pathway showed increase in proliferation and survival of tumor cells while suppressing the antitumor immune response. In this study, we aimed to analyze the chemotherapeutic effect of Fisetin combined with or without 5-Fluorouracil against IL-6 stimulated HT-29 cancer cells. Cell viability was assessed using MTT assay at different concentrations. Fisetin at the concentration of $60 \mu \mathrm{M}$ (IC50) decreased the expressions of interleukin 6 (IL-6), Janus kinase 2 (JAK-2), phosphorylated Janus kinase 2 (pJAK-2), signal transducer and activator of transcription 3 (STAT3) and Nuclear factor kappa B (NF-kB) in HT-29 cells, which were confirmed by Western blot analysis.
\end{abstract}


Furthermore, IL-6 stimulated HT-29 colon cells treatment with Fisetin regulates apoptotic cell death. Together, the results of this study revealed that Fisetin can act as a potent inhibitor of HT29 cell proliferation can be used as chemopreventive drug against colon cancer.

\section{Keywords: Colon cancer, HT-29, Fisetin, IL-6/JAK/STAT3, NF-кB, apoptosis}

\section{INTRODUCTION}

Cancer is a disease that occurs when

there is an imbalance between cell proliferation and cell death due to genetic instability, mutations, and aberrant cell signaling pathways. These events lead to tumor cell proliferation, tumor progression and metastasis [1]. Colon cancer is the most common cancer in the developed countries. According to the GLOBOCAN 2018, colon cancer found to be ranked third in the term of incidence (1.8 million new case additions) but considering the mortality rate $(881000$ deaths in 2018) colon cancer ranked as second worldwide [2]. The risk factors that are responsible for the development of colon cancer include dietary habit and lifestyle apart from the family history [3]. Colon cancer becomes prevalent in the developing countries including India due to westernized lifestyle risk factors such as high red meat consumption, smoking, alcohol consumption and lack of physical activity along with aging population [4]. By 2030, global burden of colon cancer is expected to increase by $60 \%$ to more than 2.2 million new cases and 1.1 million cancer deaths as per temporal profiles and demographic projections [5]. In contrast, dietary calcium and yogurt are associated to reduce the risk of colon cancer by mediating calcium binding to unconjugated bile acids and free fatty acids in colonic lumen as well as by activating the lactic acid producing bacteria to eliminate toxins thereby modulate gut microbiome [6]. Diet with high fiber content, fruits and vegetables also protects gut from colon cancer [7]. Significant variations in colon cancer incidence between countries largely attributed by their population dietary habits along with other risk factors, thus change in diet become prerequisite [8].

Fisetin (3,7,3', 4'-tetrahydroxyflavone) is a flavanol, a subgroup of flavonoid mostly present in the fruits and vegetables [9]. Fisetin is found in strawberries, apples, persimmons, kiwis, mango, cucumber and onions with the concentration range of 2$160 \mu \mathrm{g} / \mathrm{g}$ [10]. The highest concentration of Fisetin is present in strawberries $(160 \mu \mathrm{g} / \mathrm{g})$ followed by apple $(26.9 \mu \mathrm{g} / \mathrm{g})$ and persimmon $(10.5 \mu \mathrm{g} / \mathrm{g})$ [11]. Fisetin is reported to exhibit antioxidant activity in lung fibroblasts by 
protecting against hydrogen peroxide induced cell damage by inhibiting reactive oxygen species generation and maintaining the cellular glutathione system [12]. Fisetin is reported to exhibit virucidal property against dengue virus by inhibiting their replication at various stages of infection [13]. Fisetin possess anti-nephrotoxicity property, it has been reported that Fisetin reversed the effect of toxicity induced by cisplatin induced rat model through modulation of NF- $\mathrm{B}$, IL-6 reduction thereby improving antioxidant levels [14]. Furthermore, Fisetin exhibits antiepileptic [15], anti-adipogenic [16], antiinflammatory [17] properties and protects colon from ulcerative colitis [18].

Signal transducer and activator of transcription (STAT) proteins are a family of cytoplasmic transcription factors consisting of STAT1 to STAT6, STAT5a and STAT5b [19]. STAT is activated by receptor associated tyrosine kinase called Janus kinases (JAK), in JAK-STAT signaling, when the peptide ligand such as cytokine binds to the transmembrane receptor, this binding leads to receptor dimerization and cross activation of receptor associated JAK kinase which in turn phosphorylate tyrosine residues in the cytoplasmic region of the receptor. Those phospho-tyrosine residues act as docking site for latent cytoplasmic
STAT proteins, which are then phosphorylated by JAK [20].

Phosphorylated STAT proteins dimerize and translocates to the nucleus, where they function as transcriptional activators, including expression of target genes [21]. Interleukin-6 (IL-6) is a pleiotropic inflammatory cytokine, has central role in immune and inflammatory response, even considered as key growth factor for malignancy [22]. IL-6 binds to the IL-6 receptor through $130 \mathrm{kDa}$ signaling transducing chain, gp 130, thus their dimerization, lead to activation of intracellular signaling such as STAT-3 phosphorylation by JAK [23]. NF- $\mathrm{BB}$ is a transcription factor critical for the control of inflammation, apoptosis, tumor metastasis promotion. Dysregulated activation of NF- $\kappa B$ promotes survival of tumor cells and resistance to the cancer treatment [24]. Thus, interaction of $\mathrm{NF}-\kappa \mathrm{B}$ and STAT-3 plays important role inflammatory cell/malignant cell proliferation and their survival in cancer [25].

In this study we analyzed the effect of Fisetin on HT-29 human colon adenocarcinoma cells. Our results demonstrated that Fisetin inhibited HT-29 cell proliferation, which was associated with suppressing the NF- $\kappa \mathrm{B}$ expression, thereby decreasing their 
transcriptional activities involved with JAK/STAT-3 signaling pathway. Futhermore, Fisetin induced apoptosis in HT-29 cells was mainly associated with the involvement of Bcl-2 and BAX.

\section{Material and Methods}

\section{Cell Line}

HT-29 cell line was procured from National Centre for Cell Science (NCCS, Pune), India. The cells were grown in T75 culture flasks containing Dulbecco's Modified Eagle medium (Hi-media, Mumbai) supplemented with $10 \%$ (v/v) heat inactivated fetal bovine serum (Hi-media, Mumbai) in an atmosphere of $95 \%$ air and $5 \%$ carbon dioxide.

\section{Fisetin and IL-6 treatment}

HT-29 cells were cultured with DMEM containing $10 \%$ FBS and $1 \%$ pencillin/streptomycin. When the cells reached $60 \%$ confluence, the complete medium was changed with FBS-free medium overnight. The cells were then pre-treated with various concentrations of Fisetin in complete DMEM medium for $1 \mathrm{hr}$, followed by stimulation with $10 \mathrm{ng} / \mathrm{ml}$ IL-6 for indicated periods.

\section{Cell viability assay}

The proliferation of HT-29 was assessed by MTT assay, Jiumao Lin et al., 2015 [26].

\section{MTT solution preparation}

MTT [3-(4,5-dimethythiazol-2-yl) 2,5diphenyl tetrazolium bromide]: $0.5 \mathrm{mg} \mathrm{MTT} / \mathrm{ml}$ of serum-free DMEM medium.

\section{Procedure}

HT-29 cells were harvested and resuspended at a final concentration of $1 \times 10^{5}$ cells/ml and were seeded into 96-well plate at $100 \mu \mathrm{l} /$ well. Following the incubation for $24 \mathrm{~h}$ at $37^{\circ} \mathrm{C}$, the cells were treated with different concentrations of Fisetin and/or IL-6 for another 24h. Subsequently, 100 $\mu \mathrm{l}$ MTT $(0.5 \mathrm{mg} / \mathrm{ml})$ was added to each well. The plates were incubated at $37^{\circ} \mathrm{C}$ for $4 \mathrm{hr}$, and $100 \mu 1$ DMSO was added to dissolve the purple formazan crystals. The absorbance was then read at $570 \mathrm{~nm}$ with an ELISA reader.

\section{Experimental protocol and cell treatments}

Based on MTT assay we selected the dose $60 \mu \mathrm{M}$ of Fisetin and used for further studies. The cells were treated as follows:

Control HT-29 colon cancer cell

HT-29 cells treated with IL-6 $(10 \mathrm{ng} / \mathrm{ml})$

HT-29 cells stimulated with IL-6 (10ng/ml) and treated with Fisetin

HT-29 cells stimulated with IL-6 (10ng/ml) and treated with 5-Fluorouracil 


\section{Western Blot Analysis}

Western blot analyses for protein expression in HT-29 was assessed by the method of Song et al [27].

\section{Reagents}

a) Radio immuno precipitation buffer (RIPA) [150mM Nacl, $50 \mathrm{mM}$ Tris, 1 mM EDTA, 1\% NP 40, 0.5\% sodium deoxy cholate, $0.1 \%$ SDS, $\mathrm{pH} 7.4$ ].

b) $2 \mathrm{x}$ sample buffer with reducing agent (Sample solubilizing buffer, SSB) [125mM Tris- $\mathrm{HCl}$ ( $\mathrm{pH} 6.8), 4 \%$ SDS, $20 \%$ glycerol, $10 \% \quad \beta$-mercaptoethanol and $0.004 \%$ bromophenol blue].

c) $1 \mathrm{x}$ Tris buffered saline (TBS, $\mathrm{pH}$ 7.4): $0.2 \mathrm{M}$ Tris in $0.89 \%$ sodium chloride).

d) Wash buffer (TBST): 0.1\% Tween 20 in $1 \mathrm{x}$ TBS.

e) Blocking buffer: 5\% non-fat dry milk powder and $0.1 \%$ Tween 20 in $1 x$ TBS.

f) Antibody dilution buffer: 5\% BSA and $0.1 \%$ Tween 20 in $1 \mathrm{x}$ TBS.

g) PVDF membrane.

h) ECL kit (Millipore).

\section{Procedure}

The HT-29 cells were washed and lysed with Radio immuno precipitation buffer (RIPA) [150mM Nacl, $50 \mathrm{mM}$ Tris, 1 mM EDTA, 1\% NP 40, 0.5\% sodium deoxy cholate, $0.1 \%$ SDS, pH 7.4], Extracts were then centrifuged for $5 \mathrm{~min}$ at 14,000 r.p.m. at $4^{\circ} \mathrm{C}$. The samples were boiled for $5 \mathrm{~min}$ before loading onto gels and the equal amount of protein $(60 \mu \mathrm{g})$ were loaded and separated by $12 \%$ sodium dodecyl sulfate polyacrylamide gel electrophoresis (SDSPAGE), transferred electrophoretically to polyvinylidene difluoride (PVDF) membrane (Millipore, USA). The membranes were blocked with TBS/5\% non-fat milk (blocking buffer) for $1 \mathrm{hr}$ at room temperature and Blots were probed with various antibodies as indicated with the following primary antibodies: BAX [Rabbit polyclonal antibody at a dilution of 1:1000]; Bcl-2 [Mouse polyclonal antibody at a dilution of 1:1000]; Cyt-c [Mouse monoclonal antibody at a dilution of 1:1000]; caspase-3 [Mouse polyclonal antibody at a dilution of 1:500]; pJAK1 [Rabbit polyclonal antibody at a dilution of 1:500]; pJAK2[Rabbit polyclonal antibody at a dilution of 1:500]; JAK2[Rabbit monoclonal antibody at a dilution of 1:500]; STAT-3[Rabbit monoclonal antibody at a dilution of $1: 500] ; \beta$-actin [mouse monoclonal antibody at a dilution of 1:2000] overnight at $4^{\circ} \mathrm{C}$. The blots were then extensively washed with Tris-buffered saline with $0.1 \%$ Tween-20 and then incubated with respective [anti rabbit and anti mouse] HRP 
labeled secondary antibody (Genei, Bangalore, India) at dilution of 1:2000 for 1 $h$ at room temperature. After extensive washes in TBS-T, the bound antibodies were visualized using an enhanced chemiluminescence detection kit (Millipore, USA).

\section{Statistical Analysis}

Data were presented as mean $\pm \mathrm{SD}$ for the indicated number of independently performed experiments. All the blots were represented in the triplicate and the statistically significant was represented as mean \pm SD. Comparisons of statistical significance between groups were made by one-way analysis of variance (ANOVA). A P-value $<0.05$ was considered statistically significant.

\section{RESULTS AND DISCUSSION}

\section{Fisetin Treatment Decrease Cell viability}

Figure 1 shows the effect of Fisetin on HT-29 cell viability in the presence of IL6 as evaluated by MTT assay. IL-6 stimulation increased the cell viability significantly whereas treatment with Fisetin in the range of $20 \mu \mathrm{M}$ to $100 \mu \mathrm{M}$ decreased the cell viability of the IL-6 stimulated cells in a dose dependent manner from the 85.02 to $53 \%(\mathrm{p}<0.05)$ for 24 hours. At the dosage of $60 \mu \mathrm{M}$ the cells reached $50 \%$ of confluence. Hence, $60 \mu \mathrm{M}$ of Fisetin was fixed as an optimum dosage and used for further studies.

Effect of Fisetin on apoptotic and JAK/STAT signaling proteins

Apoptosis occurs when cells are irreparably damaged, to maintain the cell integrity by ensuring the balance between cell multiplication and cell death, thus enabling organisms to its optimal potential [28]. When the cellular apoptosis pathway such as intrinsic (mitochondrial) pathway and extrinsic (death receptor) pathway is dysregulated, this dysregulation onsets the colon cancer [29]. In intrinsic apoptotic pathway, intracellular stimuli such as irreversible genetic impairment, hypoxia, high calcium concentration, elevated oxidative stress triggers mitochondrial pathway [30]. Increase in mitochondrial porosity irrespective of the inducers, discharges cytochrome-c and other proapoptotic proteins such as BAX, Cytochrome-C, and Bid into the cytosol, subsequent caspase cascade activation, DNA fragmentation, chromatin condensation and cell shrinkage [31].

B-cell lymphoma-2 (Bcl-2) family of proteins are the regulators of intrinsic apoptotic pathway, usually these proteins are present in the endoplasmic reticulum membrane, nuclear envelope, and in 
mitochondria's outer membrane [32]. Bcl-2 pro-survival proteins regulates the release of cytochrome-c from mitochondria; thus, this protein is highly expressed in HT-29 cells. To maintain normal colonic structure, regulation of apoptosis at the top crypt and proliferation at the colonic base should be at equilibrium [33]. Abnormal expression of Bcl-2 occurs due to the dysregulation of colonic epithelial cell apoptosis leads to the colorectal carcinogenesis [34]. Thus, down regulation of $\mathrm{Bcl}-2$ can inhibit the promotion of colorectal cancer. Bcl-2 associated X (BAX) exists as inactive monomer form in the cytosol, upon stimulation either by reactive oxygen species or withdrawal of growth factor that obstructing the proapoptotic $\mathrm{Bad}$ protein, BAX protein undergoes conformational changes to form oligomers, this oligomeric form adheres to the integral membrane proteins $[35,36]$. This event induces apoptotic pore formation in the mitochondrial membrane and sequentially activates the caspase-3 signaling pathway [37]. Caspases are a family of aspartate cysteine proteases known as prototypical apoptotic executioner since they play an important role in the apoptotic response in the cell. This cascade results in the cleavage of several proteins in the cell, followed by cell disassembly, cell death and phagocytosis and removal of the cell debris [38]. Caspase cascade is activated by two routes: one from the cell surface and the other from mitochondria. Based upon the apoptotic stimulus, caspase activation pathway differs, initiator caspases (including caspases 8, 9, 10 and 12) are coupled to pro-apoptotic signals, activated caspases cleaves and activates downstream effector caspases [39]. Cytochrome-c is crucial for activating procaspase 9. Cytochrome-c that is released from the intermembrane space binds to apoptotic protease activating factor-1 (APAF1), which further recruits caspase-9 and in turn can proteolytically activate caspase-3 leading to the cellular apoptosis [40]. Thus, caspase 3 activation used in many anticancer therapies such as cytotoxic drugs, radiotherapy or immunotherapy can cause tumor cell death. Therefore, Caspase 3 activation considered as important marker to scientists, to find the efficacy of cancer treatment [41].

In this study, cytotoxic and apoptosis induction of Fisetin combined with or without 5-Fluorouracil (5-FU) on IL-6 stimulated HT-29 cells were investigated. Fluoropyrimidine 5-FU is a well-known chemotherapeutic drug used during initial treatment of colorectal cancer. The mechanism of 5-Fluorouracil involves 
disruption of normal function of DNA and RNA via misincorporation of fluoronucleotide into sequence, apart from inhibiting the function of thymidylate synthase [42]. 5-FU found to have low availability within the cells due to its rapid degradation by the enzyme dipyrimidine dehydrogenase (DPD) in the liver. Large dosage of 5-FU required to treat colorectal cancer; this higher dosage caused severe side effects to the patients in addition to being very toxic to the human body [43].

In mitochondrial apoptotic pathway, several signals cause changes in mitochondrial membrane potential and mitochondrial permeability transition resulting in the release of cytochrome c. The release of cytochrome $\mathrm{c}$ from the mitochondria is facilitated by $B a x$ and blocked by Bcl-2. The results showed that Fisetin treatment resulted in down regulation of the Bcl-2 level in the Fisetin treated IL-6 stimulated (24h) HT-29 cells (Lane 3) when compared to the IL-6 stimulated (24h) HT-29 cells (Lane 2) and control HT-29 cells (Lane 1). Further Fisetin treatment resulted in the upregulation of the Bax level in the fisetin treated IL-6 stimulated (24h) HT-29 cells (Lane 3) when compared to the IL-6 stimulated (24h) HT-29 cells (Lane 2) and control HT-29 cells (Lane 1) shown in the Figure 2. Therefore, the ratio of $\mathrm{Bcl}-2 / \mathrm{Bax}$ was significantly decreased. Cytochrome-c release is known to be key event in the mitochondria-dependent apoptosis, which in turn induces mitochondrial downstream caspase-3 activation. Pro-apoptotic (Bax) and anti-apoptotic (Bcl-2) protein determines the relative amount of cytochrome-c between the cytosol and mitochondria. As per the ratio of Bcl-2/Bax, mitochondrial permeability changes, levels of cytochrome-c was found to be increased in the Fisetin treated IL-6 stimulated (24h) HT-29 cells (Lane 3), when compared to IL-6 stimulated (24h) HT-29 cells (Lane 2) and control HT-29 cells (Lane 1) indicating the involvement of apoptosis. 


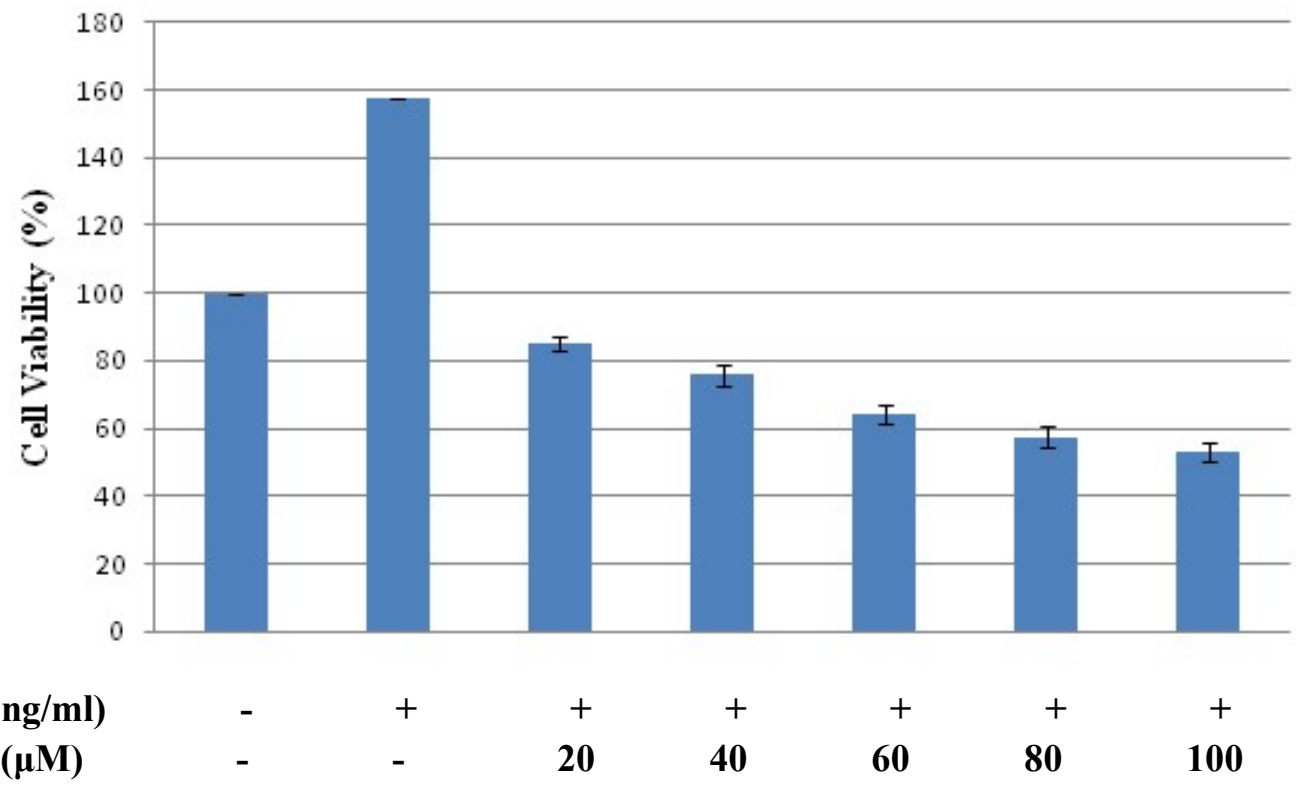

$\begin{array}{lrrrrrrr}\text { IL6 }(10 \mathrm{ng} / \mathrm{ml}) & - & + & + & + & + & + & + \\ \text { Fisetin }(\mu \mathrm{M}) & - & - & 20 & 40 & 60 & 80 & 100\end{array}$
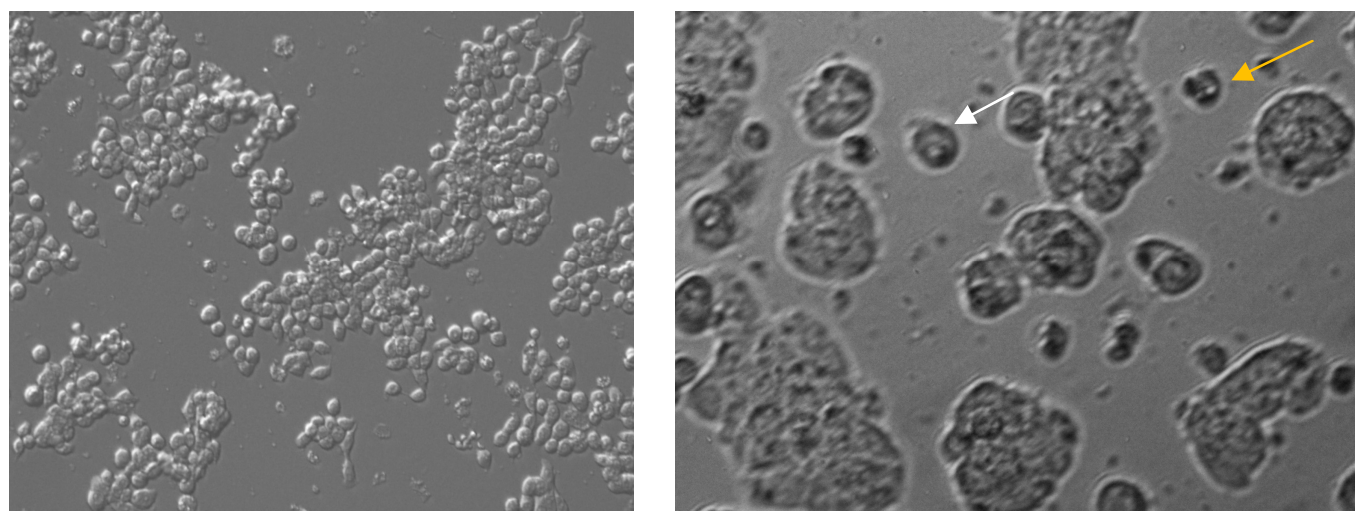

Figure 1.1 and 1.2 shows the influence of Fisetin on cell viability and cell morphology in HT-29 colon cells

1.1 HT-29 cells were treated with Fisetin at different concentrations for $24 \mathrm{~h}$ and cell viability was measured using MTT. The optimum dosage of $60 \mu \mathrm{M}$ showed $50 \%$ of confluence. Each point represents the mean \pm S.D of triplicate assays. 1.2 Microscopic analysis of HT-29 cell morphology after treatment with Fistein for $24 \mathrm{hrs}$. (a) Control cells (b) Fisetin (60 $\mu$ M in 24h) induced morphological changes in HT-29 cells. White coloured arrow indicates floating cells, since cells were reduced in number, they became round and distorted lost the contact with the adjacent cells, thus they float. Orange coloured arrow indicates the apoptotic bodies (Magnification 20X; Scale 100 $\mu \mathrm{m}$ ). 

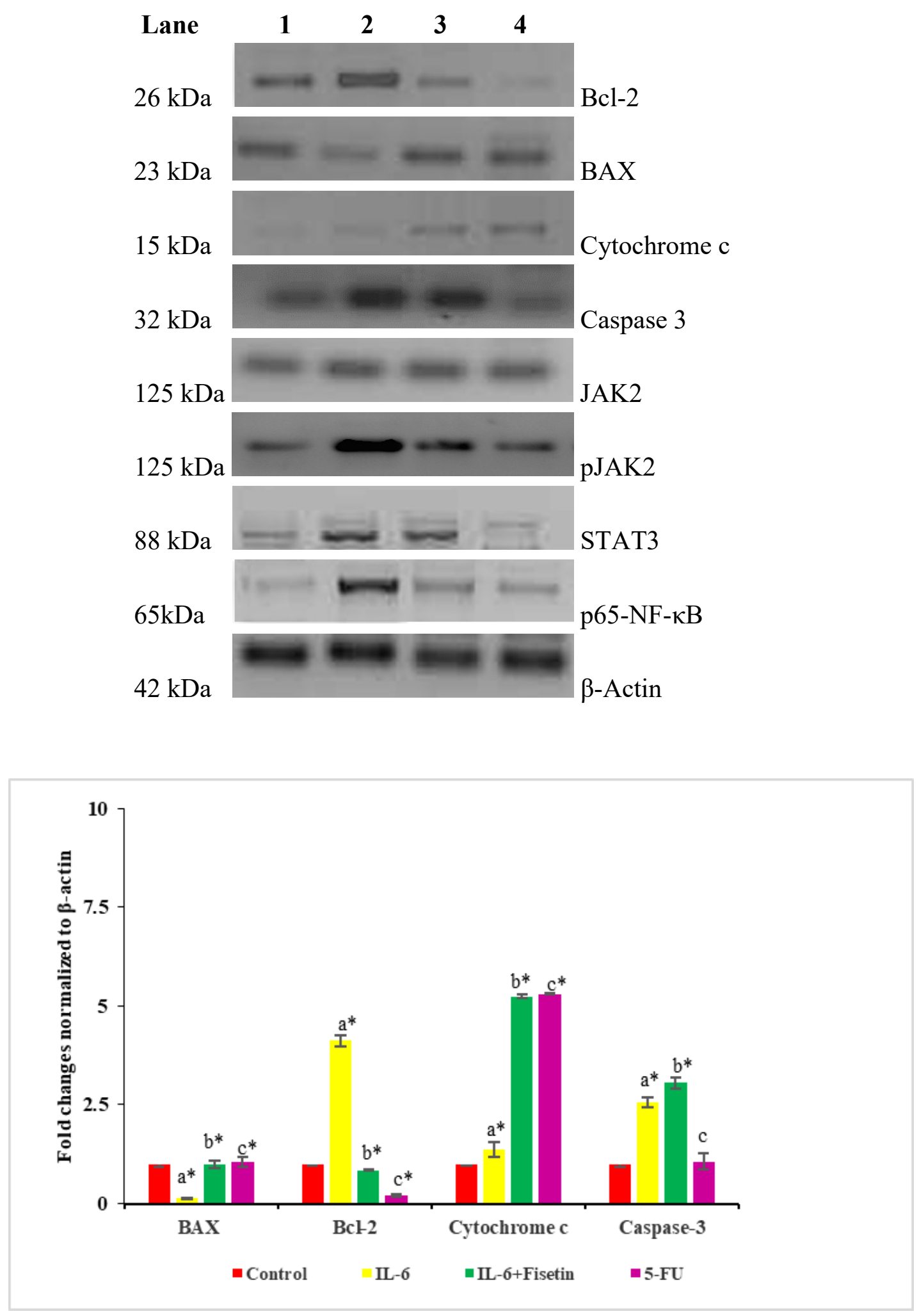


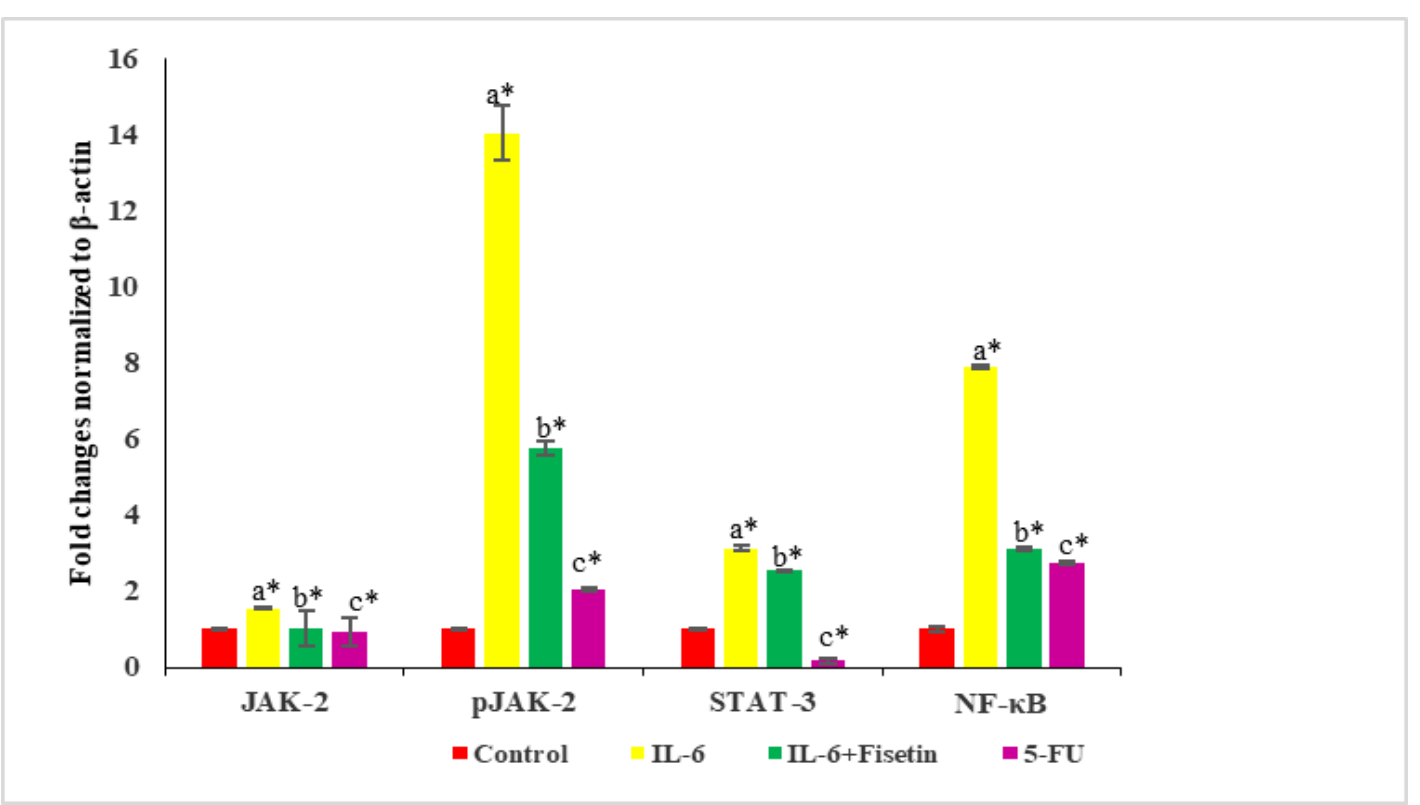

Figure 2: Shows immunoblot analysis of Bcl-2, BAX, Caspase-3, Cytochrome-c, JAK 2, pJAK, STAT-3 and $\beta$-Actin expression. Lane 1-Control, Lane 2 IL-6 treated, Lane-3 IL-6+Fisetin treated and Lane 4- 5-FU treated. Respective blots were quantified using ImageJ software. All the blots were representing the triplicate and it was represented as mean \pm

SD. Comparisons: ${ }^{a}$ Control Vs IL-6, ${ }^{\mathrm{b}}$ IL-6 Vs IL-6+ Fisetin and ${ }^{\mathrm{c}}$ IL-6 Vs 5-FU, * denotes the statistical significant $(* \mathbf{P}<\mathbf{0 . 0 5})$

Janus kinase $(\mathrm{JAK}) /$ signal transducer and activator of transcription 3 (STAT3) signaling pathway is involved in various physiological processes, including immune function, cell growth, differentiation and hematopoiesis [44]. Elevated level of IL-6 stimulates hyperactivation of JAK/STAT3 signaling, which is involved in the colorectum tumorigenesis. In the target cells, IL-6 inflammatory cytokine binds to the IL6R through gp130, thereby its dimerization, subsequent activation of STAT-3 phosphorylation by JAK [45]. Engagement of gp130 by the IL-6-IL-6-R complex results in selective activation of JAK1, JAK2, and/or TYK2 via associations of these enzymes with membrane proximal domains in the gp130 protein [46]. Activated JAKs phosphorylates tyrosine residue within the cytoplasmic part of gp130, those phosphotyrosine residues serves as docking site for STAT-3 and STAT-1. Phosphorylated STAT-3 dimerized and then translocated to nucleus, where they regulate numerous genes involved in cell cycle progression, proliferation, migration, invasion and survival [47]. STAT-3 plays a key role in nuclear retention of $\mathrm{NF}-\kappa \mathrm{B}$, they both exist as identical nuclear complexes in IL-6 promoter in starved cancer cells [48]. Moreover, interaction of STAT-3 and NF- $\kappa$ B is facilitated primarily by IL6, which forms an NF-кB-IL-6-STAT3 loop that prolongs NF- $\kappa \mathrm{B}$ activation in cancer cells. Persistently activated STAT3 maintains constitutive NF- 
$\kappa \mathrm{B}$ activity in tumors. STAT3 and NF- $\kappa \mathrm{B}$ are involved in the interplay between immune/ inflammatory and malignant cells, and activation of these transcription factors promotes CRC cell proliferation and survival. In this study, the expression of Bcl2 were increased in the IL-6 stimulated (24h) HT-29 cells in the (Lane 2) whereas treatment with fisetin significantly decreased the anti-apoptotic Bcl-2 in Fisetin treated IL6 stimulated (24h) HT-29 cells in Lane-3. The expression of BAX, cytochrome-c and Caspase-3 were significantly reduced in the IL-6 stimulated (24h) HT-29 cells in the (Lane 2) whereas treatment with fisetin increased the pro-apoptotic BAX, cytochrome-c and caspase-3 protein expression in the Fisetin treated IL-6 stimulated (24h) HT-29 cells in the (Lane 3). The expression of JAK 2, pJAK 2, STAT-3 were significantly increased in the IL-6 stimulated (24h) HT-29 cells in the (Lane 2) whereas treatment with Fisetin decreased the JAK 2, pJAK 2, STAT-3 protein expression in the Fisetin treated IL-6 stimulated (24h) HT-29 cells in the (Lane 3). Fisetin significantly downregulated the levels of JAK-2, pJAK-2, STAT-3 in the Fisetin treated IL-6 (24h) stimulated HT-29 cell line (Lane 3) when compared to the IL-6 (24h) stimulated HT-29 cell line (Lane 2).
Thus, Fisetin inhibited the NF- $\mathrm{BB}-$ STAT-3 loop by directly inhibiting STAT-3 which in turn inhibited the NF- $\kappa$ B. Fisetin inhibition of NF-кB-IL-6-STAT-3 suggesting inhibition of inflammation and inflammation induced carcinogenesis (CAC). These findings, reveal the underlying mechanism by which Fisetin inhibits the growth and progression of cancer cells, suggesting that Fisetin may have a practical clinical use for treating CAC.

\section{CONCLUSION}

The in vitro anticancer activity of Fisetin in HT-29 cells was investigated. The results of the study demonstrate that Fisetin has antiproliferative effect probably through modulation of NF- $\kappa$ B-IL-6-STAT-3. Further, studies of Fisetin can provide essential information for their possible application in cancer prevention and other inflammatory disease.

\section{REFERENCES}

[1] Gasparovic AC, Milkovic L, Rodrigues C, Mlinaric M, Soveral G. Peroxipins are induced upon oxidative stress insult and are associated with oxidative stress resistance in colon cancer cell lines. Antioxidants. 2021 Nov 22;10(1856): 1-11.doi: 10.3390/antiox 10111856 
[2] Sung H, Ferlay J, Siegel RL, Laversanne M, Soerjomataram I, Jemal A, Bray F. Global cancer statistics 2020: GLOBOCAN estimates of incidence and mortality Worldwide for 36 cancers in 185 countries. CA: A Cancer Journal for Clinicians. 2021 June;71(3): 20949.doi: 10.3322/caac. 21660

[3] Deng Y, Li S, Wang M, Chen X, Tan L, Wang L, Yang W, Chen L, He F, Yin W. Flavonoid-rich extracts from okra flowers exert antitumor activity in colorectal cancer through induction of mitochondrial dysfunctionassociated apoptosis, senescence and autophagy. 2020 Nov 3;11: 1044846.doi: 10.1039/d0fo02081h

[4] Mohsen N, Reza M. The global, regional, and national burden of colorectal cancer and its attributable risk factors in 195 countries and territories, 1990-2017: a systematic analysis for the Global Burden of Disease Study 2017. Lancet Gastroenterology and Hepatology. 2019 Feb 12;4: 913-33.doi: 10.1016/s2468-1253(19)30345-0

[5] Arnold M, Sierra MS, Laversanne M, Soerjomataram I, Jemal A, Bray F. Global patterns and trends in colorectal cancer incidence and mortality. Gut. 2016 January 5;66: 683-91.doi: 10.1136/gutjnl-2015310912

[6] Veettil SK, Wong TY, Loo YS. Role of diet in colorectal cancer incidence umbrella review of meta-analyses of prospective observational studies. JAMA Network Open. 2021;4(2):114.

doi:10.1001/jamanetworkopen.2020.3 7341

https://jamanetwork.com/journals/jam anetworkopen/fullarticle/2776517

[7] Aune D, Chan DSM, Lau R, Vieira R, Greenwood DC, Kampman E. Dietary fibre, whole grains, and risk of colorectal cancer: systematic review and dose-response metaanalysis of prospective studies. BMJ. 2011;343:d6617 available on https://www.bmj.com/content/bmj/34 3/bmj.d6617.full.pdf

[8] Lee J, Jeon J, Meyerhardt JA. Diet and lifestyle in colorectal cancer survivors. Hematology/Oncology Clinics of North America. 2015 February;29(1): 1-27.doi: 10.1016/j.hoc.2014.09.005

[9] Arai Y, Watanabe S, Kimira M, Shimoi K, Mochizuki R, Kinae N. 
Dietary intakes of flavonols, flavones and isoflavones by Japanese women and the inverse correlation between Quercetin intake and plasma LDL cholesterol concentration. The Journal of Nutrition. 2000 Sep 1;130(9): 2243-50.

doi: $10.1093 / \mathrm{jn} / 130.9 .2243$

[10] Khan N, Syed DN, Ahmed N, Mukhtar H. Fisetin: a dietary antioxidant for health promotion. Antioxidants \& Redox Signaling. 2013 Jul 10;19(2): 151-62.doi: 10.1089/ars.2012.4901

[11] Kimira M, Arai Y, Shimoi K, Watanabe S. Japanese intake of flavonoids and isoflavonoids from foods. Journal of Epidemiology. 1998 Aug 30;8(3): 168-75.doi: 10.2188/jea.8.168

[12] Kang KA, Piao MJ, Kim KC, Cha JW, Zheng J, Yao CW, Chae S, Hyun JW. Fisetin attenuates hydrogen peroxide-induced cell damage by scavenging reactive oxygen species and activating protective functions of cellular glutathione system. In Vitro Cellular \& Development Biology - Animal. 2013 Aug 27;50: 66-74.doi: 10.1007/s11626-013-9681-6
[13] Zandi K, Teoh BT, Sam SS, Wong PF, Mustafa MR, Abubakar S. Antiviral activity of four types of bioflavonoid against dengue virus type-2. Virology Journal. 2011 Dec 28;8(560): 1-11.doi: 10.1186/1743422X-8-560 available on https://virologyj.biomedcentral.com/ articles/10.1186/1743-422X-8-560

[14] Sahu BD, Kalvala AK, Koneru M, Kumar JM, Kuncha M, Rachamalla SS, Sistla R. Ameliorative effect of Fisetin on cisplastin-induced nephrotoxicity in rats via modulation of NF- $\mathrm{KB}$ activation and antioxidant defence. Plos One. 2014 Sep 3;9(9): $\quad$ e105070.doi: 10.1371/journal.pone.0105070

[15] Das J, Singh R, Sharma D. Antiepileptic effect of Fisetin in iron-induced experimental model of traumatic epilepsy in rats in the light of electrophysiological, biochemical, and behavioral observations. Nutritional Neuroscience. 2016 May 22;20: 25564.doi:

10.1080/1028415X.2016.1183342

[16] Yonesaka T, Yoshida K, Lizuka S, Hagiwara H. Effects of Fisetin on mouse lipid metabolism in vitro and in vivo. Functional Foods in Health 
and Disease. 2014 Oct 17;4(10): 429-41.

doi: $\quad$ 10.31989/ffhd.v4i10.152 https://ffhdj.com/index.php/ffhd/arti cle/view/152

[17] Gelderblom M, Leypoldt F, Lewerenz J, Birkenmayer G, Orozco D, Ludewig P, Thundyil J, Arumugam TV, Gerloff C, Tolosa E, Maher $\mathrm{P}$, Magnus $\mathrm{T}$. The flavonoid fisetin attenuates postischemic immune cell infiltration, activation and infarct size after transient cerebral middle artery occlusion in mice. Journal of Cerebral Blood Flow \& Metabolism. 2012 May;32(5): 835-43.doi: 10.1038/jcbfm.2011.189

[18] Sahu BD, Kumar JM, Sistla R. Fisetin, a dietary flavonoid, ameliorates experimental colitis in mice: Relevance of NF- $\mathrm{BB}$ signaling. Journal of Nutritional Biochemistry. 2016 Feb;28: 17182.doi:

10.1016/j.jnutbio.2015.10.004

[19] Thomas SJ, Snowden JA, Zeidler MP, Danson SJ. The role of JAK/STAT signaling in the pathogenesis, prognosis and treatment of solid tumors. British
Journal of Cancer. 2015 Jul 28;113(3): 365-71.

doi: 10.1038/bjc.2015.233

[20] Levy DE, Darnell JE. STATs: transcriptional control and biological impact. Nature Reviews Molecular Cell Biology. 2002 Sep 1;3: 651-62.doi: 10.1038/nrm909.

[21] Li WX. Canonical and noncanonical JAK-STAT signaling. Trends in Cell Biology. 2008 Nov 1;18(11): 545-51.

doi: 10.1016/j.tcb.2008.08.008

[22] Candido J, Hagemann T. Cancerrelated inflammation. Journal of Clinical Immunology. 2013 Jan;33(Suppl 1): S79-84.doi: 10.1007/s10875-012-9847-0

[23] Kishimoto T. IL-6: from its discovery to clinical applications. 2010 May;22(5): 347-52.doi: 10.1093/intimm/dxq030

[24] Liu T, Zhang L, Joo D, Sun S. NF$\kappa \mathrm{B}$ signaling in inflammation. Signal Transduction and Targeted Therapy. 2017 Jul 14;2e17023: 1-9. doi: $\quad 10.1038 /$ sigtrans.2017.23 https://www.ncbi.nlm.nih.gov/pmc/a rticles/PMC5661633/

[25] Callejas BE, Rodriguez MG, Cruz OG, Martinez SR, Barerra CAS, 
Sosa MR, Buenrostro NLD, Saucedo DM, Chirino YI, Cabrera SA, Plasencia CP, Paniagua FV, Romero LE, Terrazas LI. Helminth derived molecules inhibit colitis associated colon cancer development through NF- $\mathrm{kB}$ and STAT3 regulation. International Journal of Cancer. 2019 Dec 1;145(11): 3126-39.

doi: 10.1002/ijc.32626

[26] Lin J, Li Q, Chen H, Lin H, Lai Z, Peng J. Hedyotis diffuse Wild extract suppresses proliferation and induces apoptosis via IL-6 inducible STAT-3 pathway inactivation in human colorectal cancer cells. Oncology Letters. 2015 Apr 9;9(4): 1962-70.doi: 10.3892/ol.2015.2956

[27] Song G, Mao YB, Cai QF, Yao LM, Ouyang GL, Bao SD. Curcumin induces human HT-29 colon adenocarcinoma cell apoptosis by activating p53 and regulating apoptosis-related protein expression. Brazilian Journal of Medical and Biological Research. 2005 Dec;38(12): 1791-98. doi: 10.1590/s0100-879x2005001200007.
[28] Golstein P. Cell death in us and others. Science. 1998 Aug 28;281(5381): 1283.

doi: $10.1126 /$ science.281.5381.1283

[29] Yan X, Qi M, Li P, Zhan Y, Shao H. Apigenin in cancer therapy: anticancer effects and mechanism of action. Cell \& Bioscience. 2017 Oct 5;7: 50 .

doi: $\quad 10.1186 / \mathrm{s} 13578-017-719-\mathrm{x}$ https://pubmed.ncbi.nlm.nih.gov/29 034071/

[30] Abraha AM, Ketema EB. Apoptotic pathways as a therapeutic target for colorectal cancer treatment. World Journal of Gastrointestinal Oncology. 2016 Aug 15;8(8): 58391.doi: 10.4251/wjgo.v8.i8.583

[31] Ziegler U, Groscurth $P$. Morphological features of cell death. Physiology. 2015 May 1;19: 124-28.doi:

10.1152/nips.0519.2004.

[32] Weber GF. Cell division and survival. Molecular mechanisms of cancer. Springer, Netherlands. 2007.

[33] Rajagopalan H, Nowak MA, Vogelstein B, Lengauer C. The significance of unstable chromosomes in colorectal cancer. 
Nature Reviews Cancer. 2003 Sep

3;3(9): 695-701.

doi: $10.1038 / \operatorname{nrc1} 165$

[34] Abraha AM, Ketema EB. Apoptotic pathways as a therapeutic target for colorectal cancer treatment. World Journal of Gastrointestinal Oncology. 2016 Aug 15;8(8): 58391.doi: 10.4251/wjgo.v8.i8.583

[35] Theodorakis P, Lomonosova E, Chinnadurai G. Critical requirement of BAX for manifestation of apoptosis induced by multiple stimuli in human epithelial cancer cells. Cancer research. 2002 June;62(12): 3373-76.

doi: June 2002 available on https://cancerres.aacrjournals.org/co ntent/62/12/3373.article-info

[36] Abotaleb M, Samuel SM, Varghese E, Varghese S, Kubatka P, Liskova A, Busselberg D. Flavonoids in cancer and apoptosis. Cancers. 2019;11(1): 1-39.

doi: $\quad 10.3390 /$ cancers 110100028 https://www.mdpi.com/2072$6694 / 11 / 1 / 28 / \mathrm{htm}$

[37] Hotchkiss RS, Strasser A, McDunn JE, Swanson PE. Cell death in disease: mechanisms and emerging therapeutic concepts. The New
England Journal of Medicine. 2009 Oct 15;361(16): 1570-83.

[38] Fuchs Y, Steller H. Programmed cell death in animal development and disease. Cell. 2011 Nov 11;147(4): 742-58.

doi: 10.1016/j.cell.2011.10.033

[39] Boice A, Hayes LB. Targeting apoptotic caspases in cancer. Biochimica et Biophysica Acta Molecular Cell Research. 2020 June;1867(6): 1-15. doi: 10.1016/j.bbamcr.2020.118688

[40] Green DR, Llambi F. Cell death signaling. Cold Spring Harbor Perspectives in Biology. 2015 Dec;7(12): a006080.

doi: 10.1101/cshperspect.a006080

[41] Zhou M, Liu X, Li Z, Huang Q, Li Fang, Li CY. Caspase-3 regulates the migration, invasion, and metastasis of colon cancer cells. International Journal of Cancer. 2018 Mar 10;143(4): 921-30.doi: 10.1002/ijc.31374

[42] Longley DB, Harkin DP, Johnston PG. 5-Fluorouracil: mechanisms of action and clinical strategies. Nature Review Cancer. 2003 May;3(5): 330-38.doi: 10.1038/nrc1074 
[43] Diasio RB, Harris BE. Clinical pharmacology of 5-fluorouracil. Clinical Pharmacokinetics. 1989 Apr;16(4): 215-37.

doi: 10.2165/00003088-19891604000002

[44] Niwa Y, Kanda H, Shikauchi Y, Saiura A, Matsubara K, Kitagawa T, Yamamoto J, Kubo T, Yoshikawa H. Methylation silencing of SOC-3 promotes cell growth and migration by enhancing JAK/STAT and FAK signalings in human hepatocellular carcinoma. Oncogene.2005 Oct;24(42): 6406-17.

doi: $10.1038 /$ sj.onc. 1208788

[45] Kishimoto T. IL-6: from its discovery to clinical application. International Immunology. 2010 Apr $\quad 21 ; 22(5)$ : $\quad 347-52 . d o i:$ 10.1093/intimm/dxq030

[46] Ernst M, Jenkins BJ. Acquiring signalling specificity from the cytokine receptor gp130. Trends in Genetics. 2004 Jan;20(1): 23-32.doi: 10.1016/j.tig.2003.11.003

[47] Buettner R, Mora LB, Jove R. Activated STAT signaling in human tumors provides novel molecular targets for therapeutic intervention.
Clinical Cancer Research. 2002 Apr;8(4): 945-54

[48] Yoon S, Woo SU, Kang JH, Kim K, Shin HJ, Gwak HS, Park S, Chwae YJ. NF- $\kappa$ B and STAT-3 cooperatively induce IL-6 in starved cancer cells. Oncogene 2012 Nov 21; 31(29): 3467-81. 